\title{
Hydrocarbon Mapping on Reservoir Carbonate Using AVO Inversion Method
}

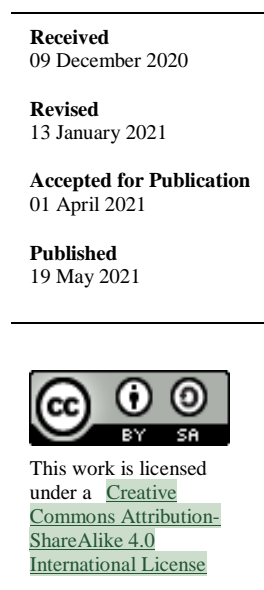

\author{
D Setyawan* \\ Department of Research and Development, Agency of Public Works and Public Housing (PUPR) \\ East Java Province, Jl. Gayung Kebonsari 56, Surabaya, 60235, Indonesia. \\ *E-mail: dendysetyawan1989@gmail.com
}

\begin{abstract}
Amplitude Versus Offset (AVO) inversion has been applied for reservoir analysis focused on the horizon carbonate Peutu and Belumai. Simultaneous inversion analysis is used to determine gas anomaly inside carbonate-rocks and it's spread laterally around target zones. It is based on the fact that small $V_{p}$ and $V_{s}$ value changes are going to show the better anomaly to identify reservoir fluid content. The AVO inversion method applies angle gather data as the input and then it is inverted to produce $P$ impedance $\left(Z_{p}\right)$ and $S$ impedance $\left(Z_{s}\right) . Z_{p}$ and $Z_{s}$ are derived to produce Lambda-Rho and Mu-Rho that are sensitive to fluid and lithology. Value of Mu-Rho between 44-65 Gpa gr/cc while value of Lambda-Rho smaller than $10 \mathrm{Gpa}$ gr/cc (for carbonate-rock filled by fluid). This research found that Lambda-Rho is the best parameter to show the existence of hydrocarbon in the case of gas. While Mu-Rho is the best parameter to show the differences in lithology.

Keywords: AVO inversion, fluid, lithology.
\end{abstract}

\section{Introduction}

Most of the producing sandstone reservoirs in Indonesia are developmental reservoirs left behind by the Dutch era [1]. The reservoir that is currently producing has decreased its annual production [2], [3]. However, this condition is contrary to the need for energy which is continuously increasing every year along with population growth [2], [4]. The exploration paradigm was looking for sandstone reservoirs as the leading oil and gas producer has begun to shift to carbonate reservoirs. The potential for carbonate reservoirs in Indonesia is relatively large because it contains more than 50\% of hydrocarbon reserves [1], [2], [5]. Carbonate reservoirs have more diverse characteristics than sandstone reservoirs, so a more complex approach is needed [6], [7].

The complexity and diversity of field conditions are some of the things that require special attention and does not just use simple data processing. However, further processing (inversion method) is needed, aiming to obtain a variety of essential information regarding hydrocarbon reserves. One of the AVO inversion method tools is the Lambda-Mu-Rho (LMR) introduced by Goodway et al. in 1997 [8]. In some cases, the inversion method using Lambda and Mu parameters and multiplying both Rho parameters has been proven to be accurate in detecting sandstone lithology and fluid content [9]-[12].

The results of previous studies show a better picture of the presence of anomalies compared to interpretation using conventional inversion methods such as Acoustic Impedance (AI) inversion method [13]-[15]. By observing the response character in the gas zone, the AVO Lambda-Rho and Mu-Rho inversion method can limit the gas zone compared to the $P$ impedance and $S$ impedance parameters (Figure 1). The LMR parameter describes Mu-Rho $(\mu \rho)$ which relates to rigidity, and Lambda-Rho $(\lambda \rho)$ which relates to incompressibility. Based on the derivation of the AVO equation, the Mu-Rho equation is expressed as

$$
\mu \rho=I_{s}^{2}
$$




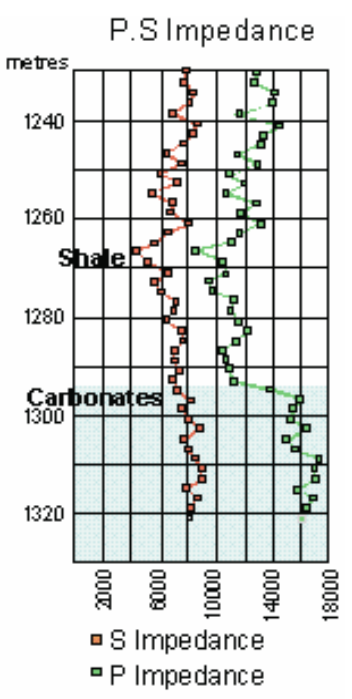

(a)

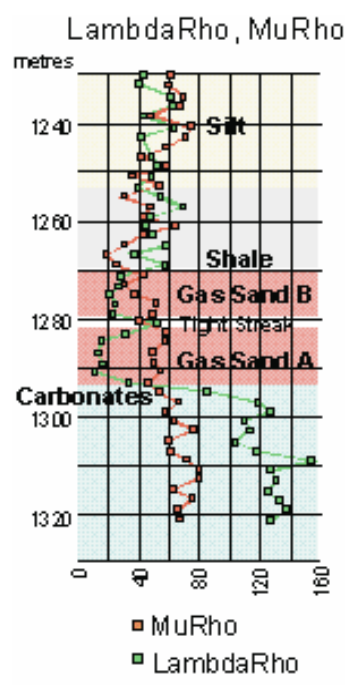

(b)

Figure 1. (a) Log $P$ impedance and $S$ impedance response characters, (b) Log Lambda-Rho and Mu-Rho characters.

and the Lambda-Rho equation is expressed as

$$
\lambda \rho=Z_{p}^{2}-2 Z_{s}^{2}
$$

which $Z_{p}$ as $P$ impedance and $Z_{s}$ as $S$ impedance [10], [11].

The LMR inversion method was applied to the North Sumatra basin, a back-arc basin bounded by the Bukit Barisan Mountains to the west, the Andaman Sea to the north, and the Malacca platform to the east. The North Sumatra Basin is a combination of pull-apart basin and half-graben basin systems formed since the late Eocene era when the Australian Ocean plate collided with the Eurasian continental plate. The Peutu and Notai Formations were thought to be important gas reservoirs in the North Sumatra basin. The Peutu Formation consists of clay and siltstone with moderate to very high carbonate content (in some places also contains the mineral glauconite). Limestone layers containing foraminifera and glauconite were formed at elevations throughout the exposure. Meanwhile, the Unai Formation, which consists of carbonate rock, sandstone and clay-limestone, is formed in the lower area. The Peutu Formation thickness varies from 35 to 50 meters at exposure to 200 to 1,100 meters in reef areas.

\section{Method}

The study was conducted to identify the gas present in the study area and distinguish the lithology type using the AVO LMR method. The steps taken in this study include several stages of implementation, starting with data preparation (well log data, seismic data, and other supporting information), well data analysis, seismic data processing by carrying out an inversion process to obtain acoustic impedance values, which are then transformed by the Mu-Rho and Lambda-Rho parameters.

\subsection{Data Collection}

This research's initial stage is to collect and prepare data and information on the research area needed for the research process. The data prepared are 3D pre-stack data (in the form of gather as the initial seismic data with $2 \mathrm{~ms}$ sample sampling method, zero phase, and Y segment format), gamma-ray log data (as well-data, velocity log, and density log to calculate the acoustic impedance of the well), and geological data of the research area (including stratigraphic data, regional geology, and structural geology of the research area which are used as references in the study) [7], [16].

\subsection{Data Processing}

Data processing in this study using the Hampson Russell V7 software. The Hampson Russell software comes with geoview, E-log, AVO, and strata features. Geoview serves as a database for storing log data that can be used in other Hampson Russell features. E-log is used for editing and analyzing log data. 
AVO is used for attribute creation and AVO analysis. In contrast, strata are used to create impedance models and perform seismic data inversion [17], [18].

Well-data processing is carried out to reduce the $P\left(V_{p}\right)$ and $S\left(V_{s}\right)$ wave velocity data so that the $\log \lambda \rho$ and $\mu \rho$ data are obtained. Crossplot is carried out on existing log data to see the parameters that best describe the target area's fluid and lithology. Seismic data is in the form of Common Deep Point (CDP) gather Pre Stack Time Migration (PSTM) with a sampling rate of $2 \mathrm{~ms}$. The angle gather process is carried out on seismic data to carry each trace in the offset area to the angle area. This process is carried out by ray tracing using the speed function. Then super gather is carried out for trace smoothing, which aims to strengthen the amplitude response. The stacking process on seismic PSTM gathers data by adding seismic traces in one CDP after Normal Move Out (NMO) correction [17], [19], [20]. The CDP stack data obtained were then correlated with well seismic tie data. After the correlation process, the target horizon is determined by picking the areas suspected of formations with hydrocarbon content. Compilation of $P$ impedance and $S$ impedance models from seismic data associated with well and horizon data as lateral boundaries. The initial model is needed for all inversion methods as a hard constraint on the final inversion result or limiting it so that the inversion result does not shift away from the model.

The seismic data inversion process in this study was carried out using a model-based method with soft constraints. Inversion is carried out by inverting time windows starting from the top of the Talangakar to the top of the basement on both reflectivities, namely the $P$ wave and the $S$ wave. The inversion process aims to obtain the $P$ wave impedance section $\left(Z_{p}\right)$ and the impedance section of the $S$ wave $\left(Z_{s}\right) . Z_{p}$ and $Z_{s}$ volumes were transformed into Lambda-Rho, Mu-Rho, and Lambda per Mu using the Goodway equation [8].

\section{Results and Discussion}

\subsection{Crossplot Analysis}

The depth section of the cross-plot results will be shown in the cross-section. This sensitivity analysis is essential to determine the parameters that can be used as indicators of lithology and fluid indicators. The cross-plot analysis of Lambda-Rho and Mu-Rho parameters can also correctly display the target area's gas fluid content. The cross-plot study results of gas anomalies are represented by a water saturation content of less than $0.6472 \mathrm{Sw}$, which is shown by yellow to green as shown in Figure 2a. The anomaly on the cross-plot is shown by the yellow ellipse circle in Figure $2 \mathrm{~b}$. A smaller water saturation value characterizes a suitable reservoir [21]-[24].

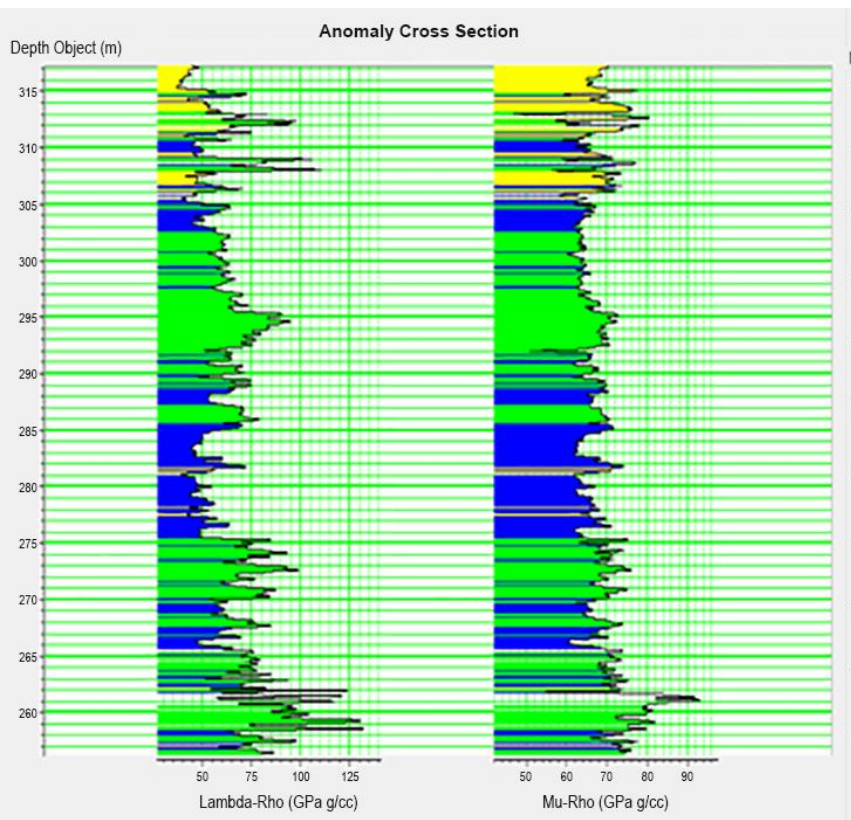

(a)

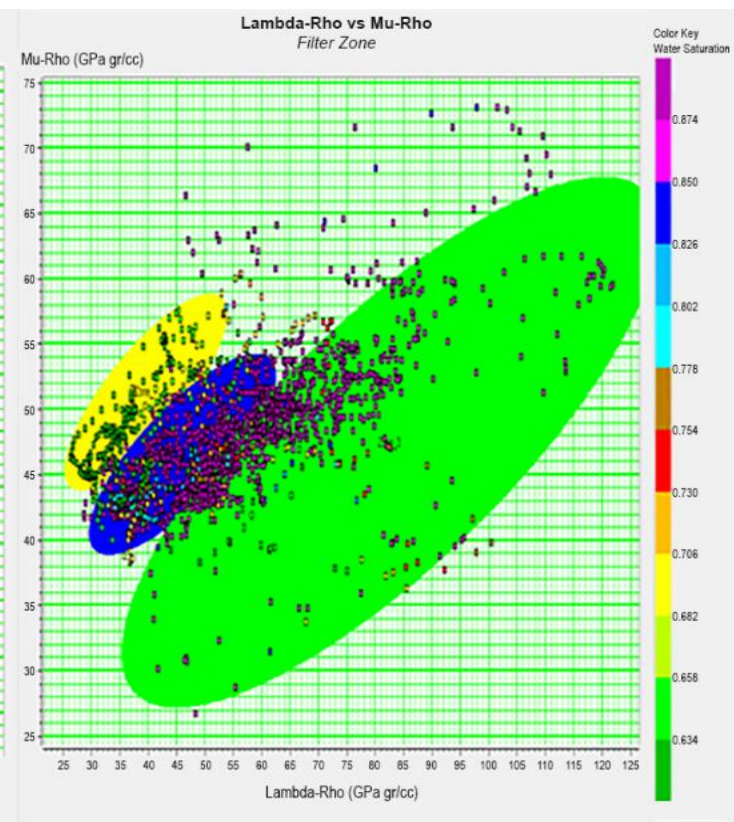

(b)

Figure 2. (a) Cross-plot between log Lambda-Rho and Mu-Rho (water saturation color scale), (b) Cross section of vertical lithology distribution. 


\subsection{Analysis of Inversion Results}

In the study area, the Belumai and Peutu formations have many fault structures and faults. When viewed from one side of the petroleum system, hydrocarbon traps are thought to be structural traps, namely traps formed due to the deformation effect of reservoir rocks such as faults. The layers of porous and permeable rocks, such as carbonates in the Peutu formation, are ridden by impermeable rocks. It acted as caprock, as indicated by the unconformity boundary between the reservoir and the rocks above it. In this case, the rocks that act as stamp rock are shale and Belumai formations which are composed of carbonate shale, sandstone, and clay-limestone.

The cross-section of the $P$ wave impedance (Figure 3) and the $S$ wave impedance (Figure 4) clearly shows that the lithology in the Peutu formation is carbonate covered by shale and the Belumai formation, which consists of carbonate shales, sandstone, and limestone clay. The carbonate bounded by the Peutu horizon and Tampur horizon are indicated by a low $P$ impedance value (reddish yellow colour) with a $P$ impedance value range of fewer than 32,500 ft/s*gr/cc and a high $S$ impedance value (purple colour) with a range of impedance values $S$ less than 25,000 ft/s* gr/cc.

The cross-sections of the inversion result ( $P$ impedance and $S$ impedance) can separate lithological variations vertically or laterally but have not been able to identify the presence of gaseous fluid. Therefore, a transformation is carried out to get the Lambda-Mu-Rho parameter value.

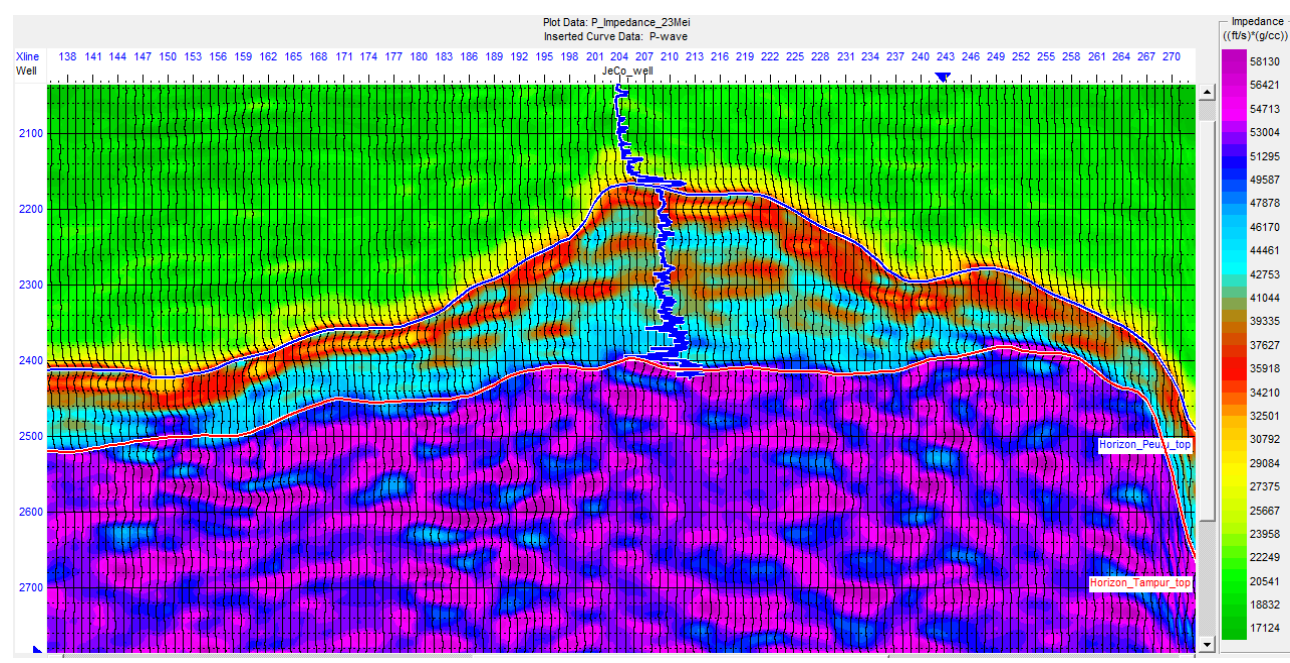

Figure 3. Cross section of the $P$ wave acoustic impedance.

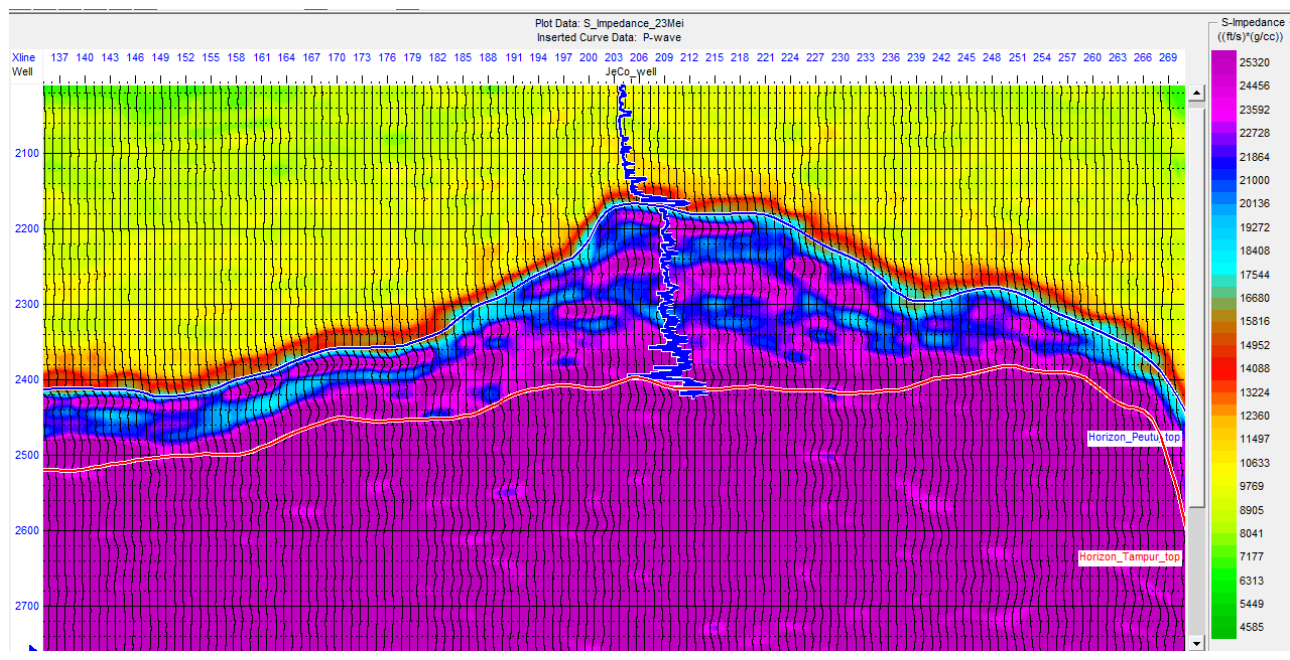

Figure 4. Cross section of the $S$ wave acoustic impedance. 


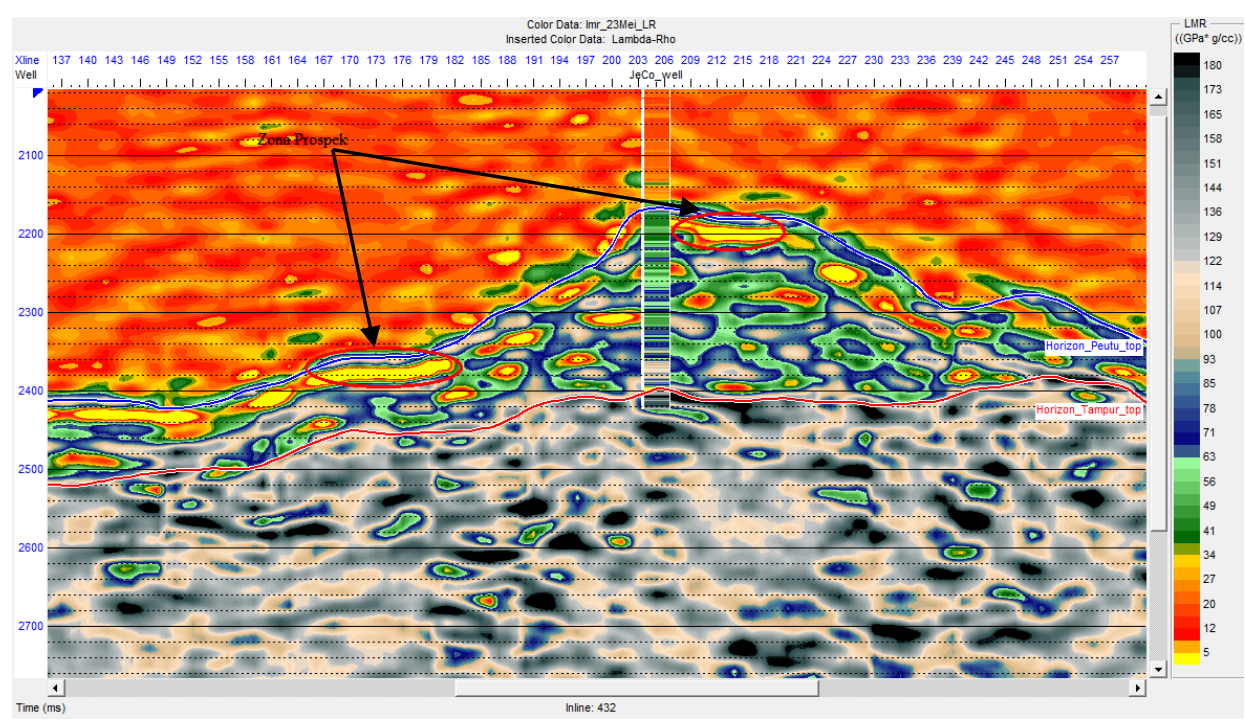

Figure 5. Target horizon anomalies at the Lambda-Rho cross-section.

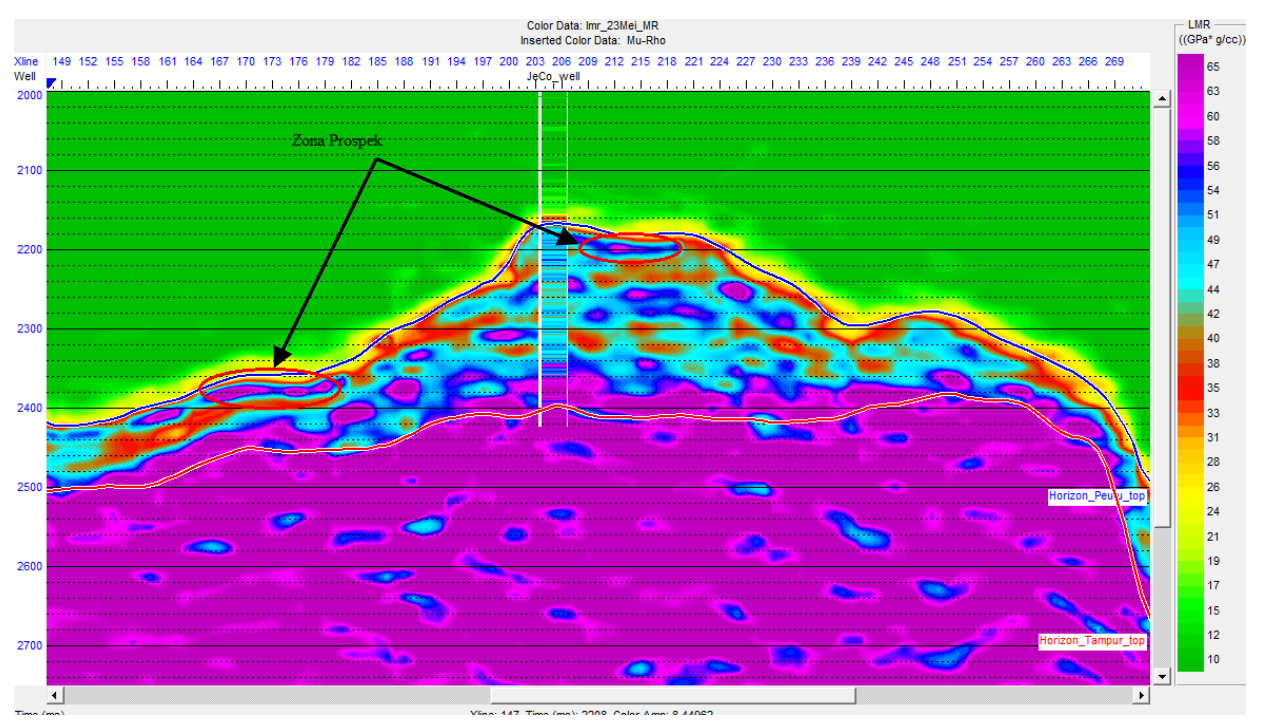

Figure 6. Target horizon anomalies at the Mu-Rho cross-section.

\subsection{Cross-sectional Analysis of Lambda-Rho and Mu-Rho}

The Lambda-Rho parameter is sensitive in classifying a fluid's presence and can show the presence of gas in the inversion cross-section. Meanwhile, the Mu-Rho parameter is an elasticity parameter that is sensitive to changes in lithology. Based on Figure 5, the anomaly area or prospect zone has a lower Lambda-Rho value (shown in yellow) than shale as the cover rock (shown in green-blue). This means that the site is a reservoir of carbonate rock that contains gas fluid. The Lambda-Rho value is relatively lower than $10 \mathrm{Gpa}$ gr/cc. Meanwhile, the zones with higher Lambda-Rho values were identified as wet zones. The analysis results on the target zone can be interpreted as an accumulation of gaseous carbonate rocks at the height of the structure (fault). Meanwhile, Figure 6 shows the Mu-Rho value in the target site near the well has a range between $44-65 \mathrm{Gpa}$ gr/cc.

\section{Conclusion}

Based on the available data, the results of the AVO LMR analysis process and the inversion process and elastic parameter estimation for fluid and lithology identification, conclude that Lambda-Rho can identify fluids where the carbonate filled with liquid will have a Lambda-Rho value lower than the carbonate that did not fill with fluid. Mu-Rho is very sensitive to lithology changes of carbonate rocks that have a higher value than the shale value. The combination of Lambda-Rho and Mu-Rho can identify hydrocarbon prospect areas, namely areas with high $\mathrm{Mu}-\mathrm{Rho}$ and low Lambda-Rho values. 


\section{References}

[1] T. Tsuji et al., "Reservoir characterization for site selection in the Gundih CCS project, Indonesia," Energy Procedia, vol. 63, pp. 6335-6343, 2014.

[2] N. A. Pambudi, "Geothermal power generation in Indonesia, a country within the ring of fire: Current status, future development and policy," Renewable and Sustainable Energy Rev., vol. 81, pp. 2893-2901, 2018.

[3] S. M. Bina, S. Jalilinasrabady, H. Fujii, and N. A. Pambudi "Classification of geothermal resources in Indonesia by applying exergy concept," Renewable and Sustainable Energy Rev., vol. 93, pp. 499-506, 2018.

[4] A. Hidayatno, A. R. Destyanto, and C. A. Hulu, "Industry 4.0 technology implementation impact to industrial sustainable energy in Indonesia: A model conceptualization," Energy Procedia, vol. 156, pp. 227-233, 2019.

[5] R. Atmadibrata, D. Muslim, R. F. Hirnawan, and A. Abdurrokhim, "Characteristics of Arun carbonate reservoir and its implication to optimize the most potential gas resource zone in Arun gas field, Aceh, Indonesia," Indones. J. Geosci., vol. 6, no. 2, pp. 209-222, 2019.

[6] H. H. Al-Attar, M. Y. Mahmoud, A. Y. Zekri, R. Almehaideb, and M. Ghannam, "Low-salinity flooding in a selected carbonate reservoir: Experimental approach," J. Pet. Explor. Prod. Technol., vol. 3, no. 2, pp. 139-149, 2013.

[7] M. A. Sebtosheikh and A. Salehi, "Lithology prediction by support vector classifiers using inverted seismic attributes data and petrophysical logs as a new approach and investigation of training data set size effect on its performance in a heterogeneous carbonate reservoir," J. Pet. Sci. Eng., vol. 134, pp. 143-149, 2015.

[8] B. Goodway et al., "Combined microseismic and 4D to calibrate and confirm surface 3D azimuthal AVO/LMR predictions of completions performance and well production in the Horn River gas shales of NEBC," The Leading Edge, vol. 31, no. 12, pp. 1502-1511, 2012.

[9] W. J. Yoon and M. Farfour, "Spectral decomposition aids AVO analysis in reservoir characterization: A case study of Blackfoot field, Alberta, Canada," Comp. Geosci., vol. 46, pp. 60-65, 2012.

[10] B. S. Ajanaku and O. J. Akintorinwa, "Determination of gas reservoir (s) using AVO inversion within "XY" field offshore Niger Delta," Pet. Res., vol. 4, no. 1, pp. 52-58, 2019.

[11] S. A. Negm, M. H. Khalil, and A. Bakr, "Gas prediction through the LMR method using poststack inversion and multi-attributes, F3 cube, North Sea, Netherlands," Arabian J. Geosci., vol. 13 , no. 14 , pp. 1-12, 2020.

[12] H. Budiman, M. Y. N. Khakim, and A. K. Affandi, "Analysis of AVO and seismic inversion for reservoir characterization (case study: EP field, South Sumatera Basin)," J. Eng. Sci. Res., vol. 2, no. 1, pp. 5-9, 2020.

[13] P. Khalid and S. Ghazi, "Discrimination of fizz water and gas reservoir by AVO analysis: A modified approach," Acta Geodaetica et Geophysica, vol. 48, no. 3, pp. 347-361, 2013.

[14] A. Gisolf, "Parameterisation for reservoir oriented AVO inversion," in 78th EAGE Conf. Exhibit. 2016, pp. 1-5, 2016.

[15] L. P. de-Figueiredo et al., "Bayesian seismic inversion based on rock-physics prior modeling for the joint estimation of acoustic impedance, porosity and lithofacies," J. Comp. Phys., vol. 336, pp. 128-142, 2017.

[16] S. Bhattacharya, T. R. Carr, and M. Pal, "Comparison of supervised and unsupervised approaches for mudstone lithofacies classification: Case studies from the Bakken and Mahantango-Marcellus Shale, USA,” J. Natural Gas Sci. Eng., vol. 33, pp. 1119-1133, 2016.

[17] C. Sayers, L. den-Boer, S. Dasgupta, and B. Goodway, "Anisotropy estimate for the Horn River Basin from sonic logs in vertical and deviated wells," The Leading Edge, vol. 34, no. 3, pp. 296306, 2015.

[18] T. Azeem et al., "An application of seismic attributes analysis for mapping of gas bearing sand zones in the sawan gas field, Pakistan," Acta Geodaetica et Geophysica, vol. 51, no. 4, pp. 723744, 2016.

[19] N. Ahmed, P. Khalid, S. Ghazi, and A. W. Anwar, "AVO forward modeling and attributes analysis for fluid's identification: a case study," Acta Geodaetica et Geophysica, vol. 50, no. 4, pp. 377-390, 2015. 
[20] P. Khalid, N. Ahmed, A. Mahmood, and M. A. Saleem, "An integrated seismic interpretation and rock physics attribute analysis for pore fluid discrimination," Arabian J. Sci. Eng., vol. 41, no. 1, pp. 191-200, 2016.

[21] A. Garg and D. J. Verschuur, "From surface seismic data to reservoir elastic parameters using a full-wavefield redatuming approach," Geophys. J. Int., vol. 221, no. 1, pp. 115-128, 2020.

[22] S. Bhattacharya and S. Mishra, "Applications of machine learning for facies and fracture prediction using Bayesian Network Theory and Random Forest: Case studies from the Appalachian basin, USA,” J. Pet. Sci. Eng., vol. 170, pp. 1005-1017, 2018.

[23] L. P. de-Figueiredo et al., "Joint Bayesian inversion based on rock-physics prior modeling for the estimation of spatially correlated reservoir properties," Geophys., vol. 83, no. 5, pp. M49M61, 2018.

[24] M. Aleardi, "Analysis of different statistical models in probabilistic joint estimation of porosity and litho-fluid facies from acoustic impedance values," Geosciences, vol. 8, no. 11, p. 388, 2018. 